\title{
An unusual upper abdominal mass (2010: 12a)
}

(C) European Society of Radiology 2010

\section{Case Report}

A 42-year-old man incidentally found an upper abdominal mass two weeks previously. He denied any overt signs or symptoms of gastrointestinal bleeding. Full blood count and renal and liver functions were within normal limits.

Physical examination: an upper abdominal palpable mass was found, the size of a pigeon's egg, movable and soft, no tenderness. He had no jaundice. He was in no acute distress and his vital signs were normal.

He underwent ultrasound and $\mathrm{CT}$ of his abdomen (Fig. 1a-c).

Fig. 1 A 42-year-old man incidentally found an upper abdominal mass two weeks previously. a: ultrasound image. b: unenhanced CT image. c: contrast-enhanced CT image
What is the diagnosis?

Readers are invited to supply one possible diagnosis via electronic means to: robert.hermans@uzleuven.be

The subject of the email should include 'Interpretation Corner' and the number given above (e.g. Interpretation Corner 2009. 1a). They should include their name, title, address, FAX and phone number. Deadline: one clear calendar month from distribution date. The names of the first 25 radiologists submitting the correct diagnosis will be published (only one from any individual centre and none from the host institution!). Three months after the initial publication of the case history, the authors will publish the final diagnosis.
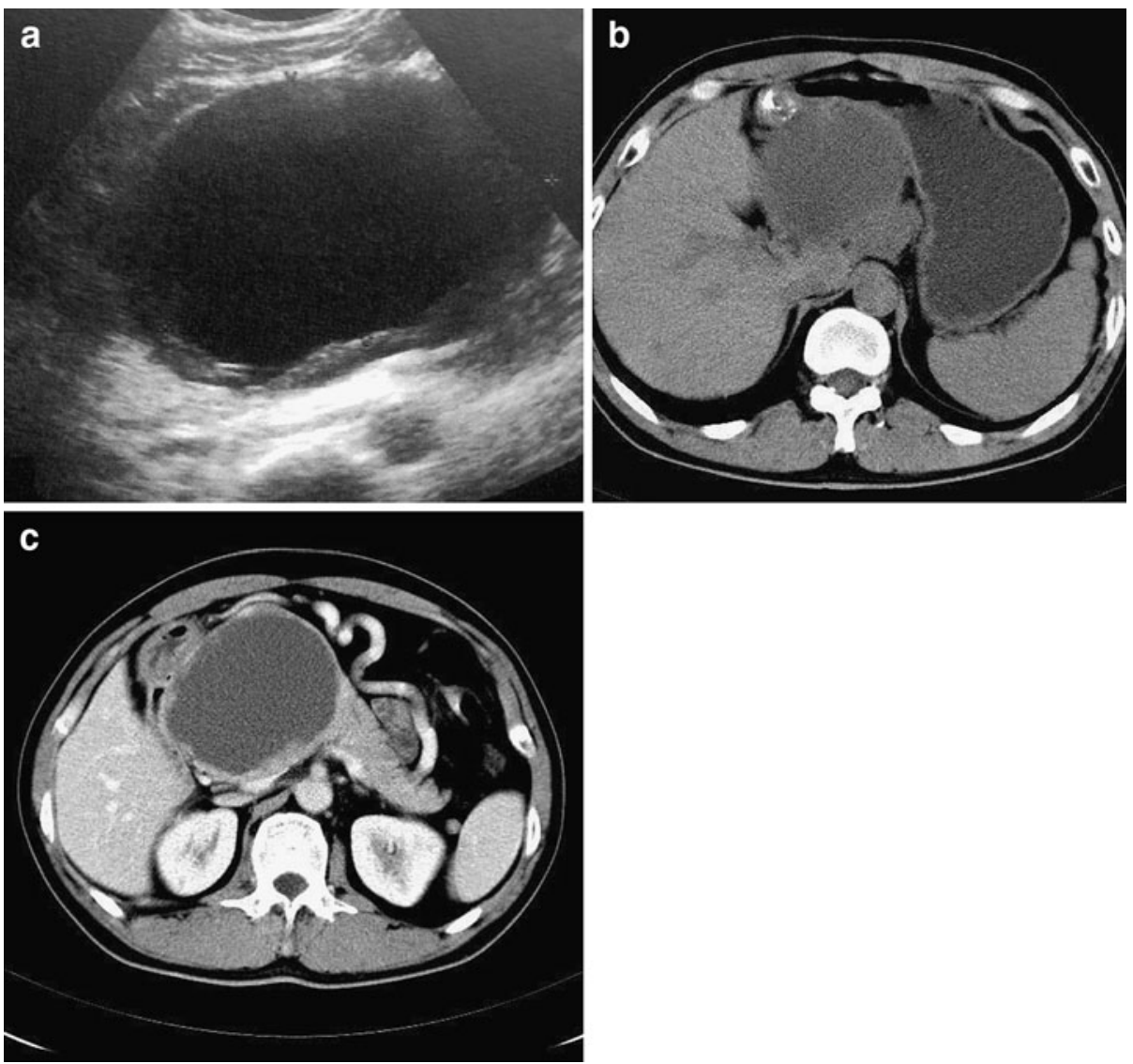